\title{
Brief Case Report: Alveolar Dehiscence in a 20 Year Old Male Patient
}

\section{UDIT JAIN}

The two main alveolar defects are: dehiscence and fenestration, which are quite commonly observed and this brief case report describes Alveolar Dehiscence in a 20 year old male patient and its subsequent treatment.

KEYWORDS: Dehiscence, Alveolar, Fenestration

\section{INTRODUCTION}

The alveolar process is an extension of the body of the maxilla or mandible, and its contour depends on the presence of teeth, apart from other factors. ${ }^{1}$ Clinical reports as well as the literature reports that encountered two main alveolar defects are: dehiscence and fenestration, which are quite commonly observed. ${ }^{2}$

An alveolar dehiscence is described by lack of the facial or lingual alveolar cortical plate, which results in a denuded root surface, and on the other hand, an alveolar fenestration(derived from the Latin word fenestra, meaning "window") is a circumscribed defect of the cortical plate exposing the underlying root surface but not involving the alveolar margin of the maxillary/mandibular bone. $^{3}$

This brief case report describes the presence of alveolar dehiscence in the mandibular left molar region of a patient completely exposing the distal root of the mandibular first molar.

\section{CASE REPORT}

The case (2o year old male patient) was reported in a dental screening camp which was referred to a private clinic for surgical extraction. Clinical examination revealed the distal root of the mandibular left first molar completely exposed from the buccal surface (figure 1 ) and necessitating surgical removal. The laboratory reports of the patient were reported to be normal and the surgical extraction went uneventful with the patient satisfied with the results. Prior to reporting this case, a written consent was taken from the patient before publishing the case and confidentiality was assured.

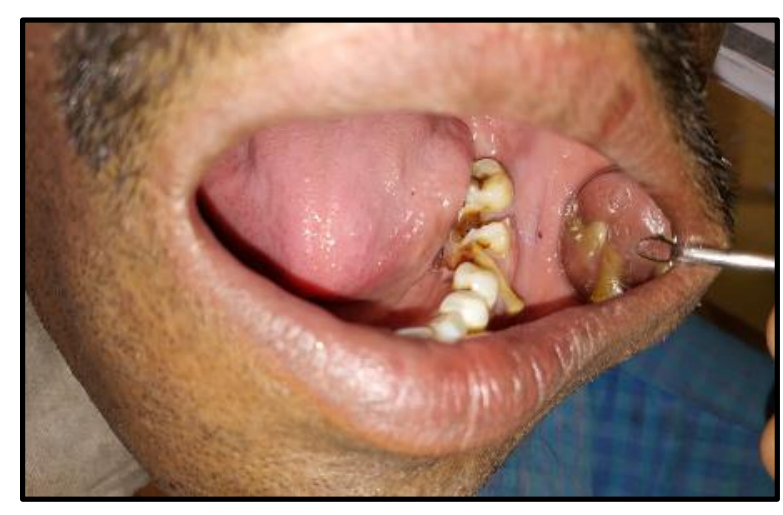

Figure 1. Dehiscence in the distal root of left mandibular first molar

\section{DISCUSSION}

Clinicians report that that exposed root tips favor the accumulation of plaque and calculus which prevents the reformation of mucosal covering which, however, in our case no plaque or calculus was observed in the exposed root surface, and is in disagreement with the above mentioned statement. ${ }^{4}$

The exposed root surface was considered for extraction as it had a very poor prognosis (due to the missing crown and mesial root), and could not be managed by conventional techniques. The tooth was asymptomatic in nature and the patient, being a farmer did not agree for extended follow ups and wanted to get the exposed tooth extracted itself.

The presence of root dehiscence in such an age is a rare finding and the reasons attributed to it 
could be attributed to alveolar bone development, composition, structure, maturation and aging apart from an improper oral hygiene of the patient. ${ }^{5,6}$

\section{REFERENCES}

1. Brand RW, Isselhard DE. Anatomy of Orofacial Structures. 7th ed. St. Louis: Mosby; 2003.

2. Edel A. Alveolar bone fenestrations and dehiscence in dry Bedouin jaws. J Clin Periodontol. 1981;8:491-9.

3. Bharti R, Chandra A, Tikku AP, Prasad V, Shakya VK, Singhal R. Management of mucosal fenestration with external root resorption by multidisciplinary approach. BMJ Case Rep. 2014; 2014: bcr2014206259.

Source of support: Nil, Conflict of interest: None declared
4. Chen G. Fang CT, Tong C. The management of mucosal fenestration: a report of two cases. Int Endod J. 2009;42(2):156-64.

5. Rupprecht RD, Horning GM, Nicoll BK, Cohen ME. Prevalence of dehiscence's and fenestrations in modern American skulls. J Periodontol. 2001; 72 (6): 722-9.

6. Fuhrmann RA, Wehrbein $H$, Langen HJ, Diedrich PR. Assessment of the dentate alveolar process with high resolution computed tomography. Dentomaxillofac Radiol. 1995;24(1):50-4.
Cite this article as:

Jain U. Brief Case Report: Alveolar Dehiscence in a 20 Year Old Male Patient. Int Healthc Res J. 2018;2(9):215-216. doi: 10.26440/ihrj.v2i9.o1B

\section{AUTHOR AFFILIATIONS:}

${ }^{*}$ Corresponding Author:

Dr. Udit Jain

House no 56

Lane no 4

Sabzi mandi, Aligarh
For article enquiry/author contact details, e-mail at: editor.ihrj@gmail.com,editor@ihrjournal.com 